\title{
The Role of Network Public Opinion Monitoring of Ideological and Political Education in College Students
}

\author{
YouQingming, XieDan \\ Nanchang Institute of Science \&Technology,Nanchang 330108,China
}

Key words: Ideological and political; network public opinion; interactive platform; mobile network; Internet

\begin{abstract}
In order to strengthen the effectiveness of ideological and political education in Colleges, and promote the education quality, it is proposed a ideological and political education and teaching methods based on network public opinion monitoring, combined with the current Internet technology, which use interactive platform such as QQ, Wechat, WeiBo and forum, and use Internet, cloud and mobile networks to investigate questionnaires, and timely understanding of College Students' Network Ideological and political thought. Through the research on the network public opinion of University, it is put forward a data mining method of College Students' Ideological and political network public opinion based on the EM method. The questionnaire data were characteristic analyzed, and finally College Students' Ideological and political education countermeasures are summarized based on network public opinion monitoring, which provide a kind of new method for ideological and Political Education work in Colleges and universities.
\end{abstract}

\section{Introduction}

With the rapid development of Internet, network forum, keep abreast of news, blog posts and other individual discourse expression form of increasingly mature, more and more Internet users are willing to express their understanding and views, opinions and suggestions of the society through the channels, which indicates that the network public opinion has been extent to the network virtual space from the field of social daily life. Internet has become an important channel for the university to gain knowledge and information, and the ideological and political network public opinion is a network comment or view point which is connected with the ideological and political. Ideological and political education has been carried out in Universities, we need to correctly grasp the characteristics of the network education, and actively use the network public opinion monitoring method, so that the network can become a good medium for Colleges and universities to carry out Ideological and political education in new period of time.

\section{The ideological and political education work based on the network public opinion}

With the popularity of Internet in University, network public opinion has become the emerging power of influence college students' Ideological and political behavior, the influence of network public opinion on College Students' Ideological and political work is mainly reflected in the forum, blog, QQ and Wechat.

In recent years, the central government has paid more and more attention to public opinion on the network. Hu Jintao has proposed that strengthening internet ideological and public opinion and the construction of the ideological front, and grasp the initiative of network public opinion, and 
active use of new technology of network, and increase the network of positive publicity, positive to the ideological and political opinion formation. According to the campus environment, the theory of big data mining the data of network public opinion has been used in this paper, through the objectively public opinion monitoring of letter, QQ, Weibo, forums etc..In order to collect relevant ideological and political information, and network ideological and political network public opinion sowing rules, which provide theoretical basis for the timely guidance and better monitoring of network public opinion.

At present, there are still some problems in the ideological and political education in Colleges and universities, which are mainly embodied in the ideological cultural and quality of teachers. With the penetration of Western cultural values, and the spread of Internet information culture, students' thought has been floating, which is not conducive to the development of traditional culture and ideological and political education work. From the aspect of the quality of the teachers that in work of, College Ideological and political education, the social experience of young teachers is shallow, and lack of work experience, the quality and level of Ideological and political theory needs to be further improved. Therefore, it is significant for Colleges and universities to introduce network public opinion into the process of Ideological and political education of university students, in the aspect of carrying out ideological and political education work, and effectively monitoring students ideological and political performance, and establishment analysis and evaluation mechanism.

\section{Network public opinion data mining algorithm based on EM}

A lot of data will be generated in the monitoring of Ideological and political network public opinion, so we need to combine data mining algorithms for network public opinion data analysis and processing, so as to get more valuable characteristics. EM (Expectation Maximization) algorithm is an improved algorithm of k-means clustering algorithm, which is slightly different with K-means algorithm. It's not assigned to a cluster in the each object, but to use the data membership probability weights assigned to the object, based on weighted method to calculate. In the EM algorithm, there is no strict boundary between clusters. The probability that object $O_{i}$ attached to the cluster $C_{i}$ is shown as formula (1):

$$
P\left(O_{i} \in C_{j}\right)=p\left(C_{j} \mid O_{i}\right)=\frac{p\left(C_{j}\right) p\left(O_{i} C_{j}\right)}{\sum_{k} p\left(C_{k}\right) p\left(O_{i} C_{k}\right)}
$$

In formula (1), $P\left(O_{i} \mid C_{j}\right)=N\left(m_{j}, \sigma_{j}\left(O_{i}\right)\right)$ follows a normal distribution that mean value is $m_{j}$, and the variance is $\sigma_{j}$, the expression for mean value $m_{j}$ in the cluster $C_{i}$ is shown as formula (2):

$$
m_{j}=\sum_{i=1}^{n} O_{i} \frac{p\left(O_{i} \in C_{j}\right)}{\sum_{i=1}^{n} O_{i} \in C_{j}}
$$

In formula (2), $n$ is the number of objects, the basic idea of the EM algorithm is first of college students in the network public opinion data for the initial estimates, then repeat the $\mathrm{E}$ and $\mathrm{M}$ steps, until the data convergence, where e is expected to step, $\mathrm{M}$ is the step, the algorithm described as following:

Algorithm: EM algorithm;

Input: College Students Ideological and political education network public opinion data, data objects D, the number of clusters $\mathrm{K}$;

Output: K network public opinion characteristic data. 
The specific process of the algorithm is

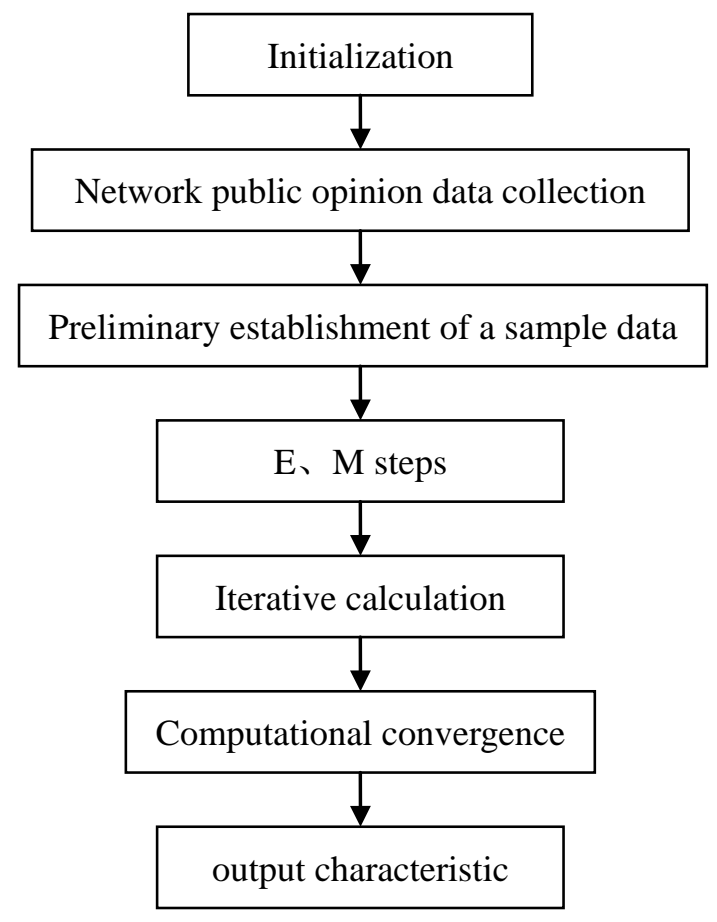

Fig. 1 The flow chart of EM network public opinion data processing

Fig. 1 shows the network public opinion data processing. According to the relevant procedures in the map, the specific steps of the EM algorithm is summarized as follows:

(1) Preliminary estimate of the data of network public opinion, randomly selected $K$ different data feature objects from $\mathrm{D}$, as $K$ feature sample data sets $C_{1}, C_{2}, \ldots, C_{k}$, its center respectively are $m_{1}, m_{2}, \ldots, m_{k}$, estimating the variance $\sigma_{1}, \sigma_{2}, \ldots, \sigma_{k}$ of $K$ sample data set;

(2) Repeat steps

1) Step E: calculate $P\left(O_{i} \in C_{j}\right)$, according to the calculation $P\left(O_{i} \in C_{j}\right)$, the object $O_{i}$ is assigned to a sample data set $C_{j}$;

2) Step M: using E probability calculation to estimate $m_{j}$ again;

(3) If Unite parameters do not change, the result is convergence, end of iterative calculation.

The ideological and political network public opinion data mining can be completed through the above steps. In the next section, the data characteristics will be analyzed based on network survey data by using the algorithm.

\section{Research on the monitoring of College Students' Ideological and political network public opinion data}

In order to further study the influence of network public opinion on College Students' Ideological and political emotion, the relevance of network public opinion and college students Ideological and political emotion factors will be got mainly by using network questionnaire form, under the environment of big data, and using Internet and mobile communication environment to quantify the network public opinion emotion in this study. 
Tab.1 Model measurement project

\begin{tabular}{|c|c|}
\hline Variable & Measure item \\
\hline A1 Ideological and political emotion level & Intensity, attention, hot spot \\
\hline A2 The direction of Ideological and political emotion & $\begin{array}{c}\text { Do not care, concern, intensity of } \\
\text { concern, extreme anger }\end{array}$ \\
\hline B1 The focus of Ideological and political emotion & Oneself, society, others \\
\hline B2 Ideological and political affective reaction & $\begin{array}{c}\text { Social development, focus on self } \\
\text { Focus on people's livelihood }\end{array}$ \\
\hline
\end{tabular}

Table 1 shows the measurement items of the questionnaire, the questionnaire is provided by cloud, mobile networks and Internet, and data extraction on the campus BBS, Wechat, QQ and Weibo, finally, the recovered investigation file for data mining, and the questionnaire reliability is tested by AVE、CR coefficient, the results is shown in Table 2.

Tab. 2 The reliability test results

\begin{tabular}{|c|c|c|}
\hline Variable & CR & AVE \\
\hline A1 Ideological and political emotion level & 0.85 & 0.75 \\
\hline A2 The direction of Ideological and political emotion & 0.92 & 0.78 \\
\hline B1 The focus of Ideological and political emotion & 0.88 & 0.82 \\
\hline B2 Ideological and political affective reaction & 0.87 & 0.85 \\
\hline
\end{tabular}

Table 2 shows the reliability of the questionnaire test results. From the results, it can be seen between 0.75-0.92 metric item reliability coefficient, suggesting that investigation files with high reliability and the validity of the results as shown in Table 3 shows.

Table 3 The validity test results

\begin{tabular}{|c|c|c|c|c|}
\hline variable & A1 & A2 & B1 & B2 \\
\hline A1 & 0.85 & & & \\
\hline A2 & 0.76 & 0.87 & & \\
\hline B1 & 0.65 & 0.66 & 0.91 & \\
\hline B2 & 0.73 & 0.52 & 0.49 & 0.89 \\
\hline
\end{tabular}

Table 3 shows the validity test results, we can be seen by factor analysis results, on the diagonal, the AVE values are greater than 0.8, which is greater than the correlation between each factor in accordance with the rule of validity. We can see that there is a significant correlation between Ideological and political emotion and the network public opinion and the relationship is more closely through the analysis.

\section{Countermeasures of College Students' Ideological and political education based on network public opinions}

There is a close link between network public opinion and college students' Ideological and political. Therefore, when carrying out ideological and political education work colleges and universities, we need to develop relevant countermeasures, combined with Internet technology, which can be mainly summarized from the following four aspects:

(1) Grasp the inherent law of the ideological and political network public opinion in college

In the ideological and political network public opinion, the small campus events will become the focus content of school, and many of them are negative resentful comments, which will easily cause the students' dissatisfaction and resentment, so if we want to do a good job in Ideological and political education work, we need to first from the actual start and camp made a good network environment. The monitoring information of the network public opinion should be timely fed back 
to the majority of teachers and students and staff, then we can occupy the network position, and strengthen network management, and promote the construction of spiritual civilization of network culture.

(2) Promote the importance of network of political education

We can establish a network of specialized construction team to strengthen students ideological and political network construction, and strive to build ideological and political network platform, and promote the interactive learning of Ideological and political education, and establish Ideological and political education homepage and forum, and promote the exchange of students' Ideological and political.

(3) Open up new ways of Ideological and political education using the network

Schools can use the Internet platform, and construct students' psychological education platform, the reasonable organization psychological test, and carry out targeted education for students with poor ability to share and students with no firm political beliefs, and actively explore the network psychology crisis early warning and intervention mechanism. To strengthen the ideological and moral education, so that students have a good ideological and political quality, and strengthen the campus network moral deeds propaganda, and carry out the activities of network to move the campus figure.

(4) Effectively carry out the ideological and political education using the network

Strengthen the construction of online work position, broaden the way of work. Teachers of Ideological and political education work of thematic studies and make full use of the QQ, micro channel, micro blog interactive platform, timely and students were sharing, give full play to the positive role of student cadres, timely guidance problem of Ideological and political education of the students, give full play to the important role of Science industry and trade supervision, to strengthen the construction of rules and regulations, to ensure the smooth progress of the work of the network ideological and political education, so as to improve the teaching method in Ideological and political education.

\section{Conclusions}

A new ideological and political teaching method based on network public opinion has been proposed in this study, combined with modern QQ, Wechat, Weibo , forum and other interactive platform, based on Internet, mobile Internet and cloud. network public opinion data characteristics mining algorithm based on EM has been proposed in the form of investigation documents. Through the analysis of the questionnaire survey of the characteristics of the data, we found that there is a close link between network public opinion and the college students' Ideological and political. Therefore, when ideological and political education work is carried out in colleges and universities, we need to formulate relevant countermeasures combined with Internet technology, and improve the teaching quality of ideological and political education.

\section{Acknowledgement}

The work was supported by the the teaching reform research project of higher education in Jiangxi province in 2015 with the project number JXJG-15-27-3 and the project name Research on the Path of Iimproving the Teaching Effectiveness of Ideological and Political Theory Course in Colleges and Universities in Big Data Era. 


\section{References}

[1] Chen Yijin, Cao Shujin, Chen Guihong. Internet public opinion mining user reviews: sentiment analysis research J. Document, Information \& Knowledge , 2013 (6): 90-96

[2] Wang Lancheng, Xu Zhen. The tendency analysis of theme network public opinion based on emotion ontology J. Information and control, 2013 (1): 46-52

[3] He Tian Xiang, Zhang Hui, Li Bo, etc.. A sentiment analysis of online public opinion based evolution analysis method [J]. Software Guide, 2015 (5): 131-134.

[4] Zhang Xiaoxia, Wang Mingyang, He Huixin. The combination of the key nodes of emergency sentiment analysis of Internet public opinion mining J. Journal of Xinjiang University (Natural Science Edition), 2015 (2): 1-6

[5] Cao Xueyan, Duan Feifei, Fang Kuan, etc.. Network forum, from the perspective of identifying the key node of unexpected events of public opinion and classification [J]. Library and Information Service Abroad, 2014, 58 (4): 65-70.

[6] Huang Weidong, Chen Lingyun, Wu Meirong. Study on the emotional evolution of online public opinion topic (J). Journal of Intelligence, 2014 (1): 102-107

[7] Wang Junxiu. Social psychology: a study of social psychology in Transitional Society [J]. Sociological Studies, 2014 (1): 104-124,244

[8] Tang Tao. Research on network public opinion analysis method based on large data (J). Modern Information, 2014 (3): 3-11

[9] Yang Jing, Li Wenping, Zhang Jianpei. The cloud model method of canonical correlation analysis of large data (J). Journal on Communication, 2013, 34 (10): 154-170

[10] Yao Fei, Daiyuan. Based on the security of public opinion on the network information mining and evaluation index system research [J]. Information Studies: Theory \& Application.2008,03:31-32

[11] Wu Shaozhong, Li Shuhua. Research on the early warning mechanism of Internet public opinion [J]. Journal of People's Public Security University of China (Natural Science Edition).2008,03:38-42

[12] Xu Xin, Zhang Chengzhi, Li Wenjing. Research on the network public opinion review and Prospect of [J]. Information Studies: Theory \& Application. 2009,03:115-120

[13] Ding Jie, Xu Jungang. IPSMS: Design and Implementation of a network public opinion monitoring system[J]. Computer Applications and Software, 2010,27 (4): 188-190

[14] He Yao, Wang Wenqing, Xue Fei. Study on massive data mining based on cloud computing[J]. Computer Technology and Development 2013,23 (2): 69-72

[15] Ding Yan, Yang Qingping, Qian Yuming. Based on cloud computing data mining platform architecture and its key technology [J]. ZTE communications, 2013,19 (1) 53-60

[16] Yin Chao, Huang Biqing, Liu Fei, et al.. The common key technologies of small and medium-sized enterprises cloud manufacturing service platform[J]. Computer Integrated Manufacturing Systems 2011,17 (3): 495-503.

[17] Gao Wei, Kang Qian. The application of computer software and CD-ROM on the embedded system[J]. 2014, 14 (08):69-70. 